\title{
Haemorrhage associated with meningioma: a case report and review of the literature
}

\author{
T L HELLE AND F K CONLEY
}

From the Section of Neurosurgery, Palo Alto Veterans Administration Medical Center, Palo Alto, California and the Division of Neurosurgery, Department of Surgery, Stanford University Medical School, Stanford, California

SUMMARY A case of haemorrhage into a parasagittal meningioma treated by surgical resection is presented. A review of the literature found 43 additional cases of meningioma associated with haemorrhage. By correlating these cases with those from another large series of meningiomas classified by histological type and location, an estimation of the "relative bleeding tendency" of certain classes of meningiomas was made. Haemorrhage associated with meningioma is a serious complication and proper treatment consists of evacuation of the haematoma with resection of tumour.

Although much is known about the natural history of meningiomas, the behaviour of such tumours in a given patient depends on many factors: location, size, histology, and cytology. ${ }^{1}$ There is little information about haemorrhage associated with meningiomas and the influence of such haemorrhage upon patient outcome. We present a patient who bled into a parasagittal meningioma, and review the available literature on haemorrhage associated with meningiomas.

\section{Case report}

The patient is a 77 year old Filipino male who presented to the Palo Alto Veterans Administration Medical Center in April, 1978, complaining of the sudden onset of weakness of the left leg. Five years before he had been admitted to the hospital for a similar left hemiparesis which had resolved. Neurological evaluation on admission revealed an alert, oriented patient with left hemiparesis and hyperreflexia which was greater in the lower extremity. Sensation was intact and there was no papilloedema. A right parasagittal mass, which was faintly seen on a non-contrast CT scan, exhibited marked contrast enhancement (fig 1a and $1 \mathrm{~b}$ ). Angiography revealed a faint blush in the same area. All studies indicated a parasagittal meningioma. The patient refused surgery and was followed closely as an outpatient.

Address for reprint requests: Dr Frances $\mathrm{K}$ Conley, Section of Neurosurgery, Palo Alto Veterans Administration Medical Center, 3801 Miranda Avenue, Palo Alto, California 94304, USA.

Accepted 20 March 1980
Over the next three months his hemiparesis improved but not completely.

In July, 1978, the patient had a sudden exacerbation of the left hemiparesis associated with headache. Neurological evaluation demonstrated only left hemiparesis and hyperreflexia. The leg was more involved than the arm and was more impaired distally than proximally. A repeat CT scan without contrast showed a diffuse high density lesion consistent with the presence of blood within the previously demonstrated tumour mass (fig 2). Progression of the left hemiparesis led to surgical exploration

At surgery an egg-shaped tumour was found attached to the falx. The superior sagittal sinus was patent. Tissue necrosis and yellow discoloration due to previous haemorrhage were found within the tumour capsule. The adjacent motor cortex was atrophic, but there was no evidence of either recent or old intracerebral or subdural haemorrhage. Approximately $95 \%$ of the necrotic tumour was resected, leaving only a small portion attached to the falx at its inferior aspect next to the corpus collosum. The tumour was a transitional meningioma with prominent vascularity, but no histological features of malignancy (fig 3). None of the tiny tumour fragments submitted contained haemosiderin or old red blood cells.

Postoperatively the patient had a profound left hemiparesis which improved over the next four months. At discharge he had distal left lower extremity paresis but was able to walk. A CT scan 12 months postoperatively showed no evidence of residual or recurrent tumour. 

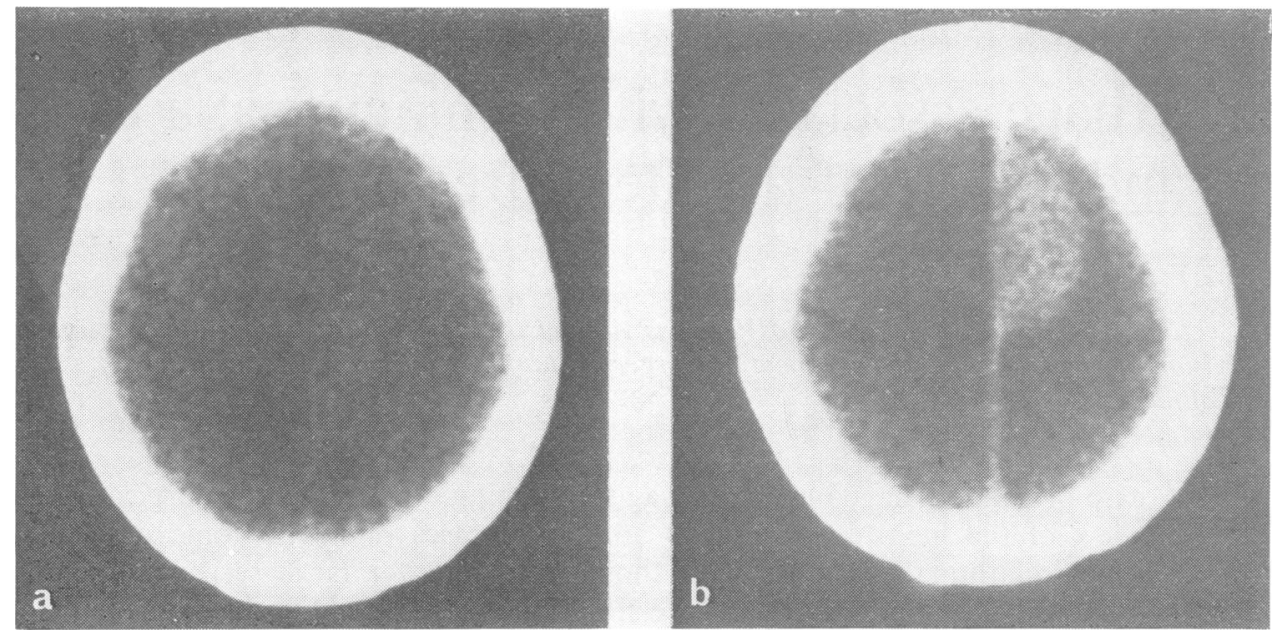

Fig $1 \mathrm{a}$ and b CT scans of patient in April 1978, showing the right parasagittal mass. 1a is without contrast enhancement; $1 \mathrm{~b}$ is with contrast enhancement.

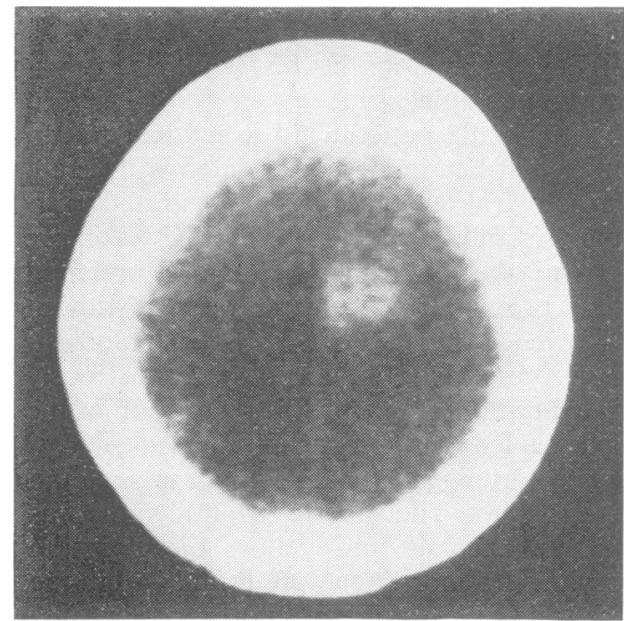

Fig 2 Noncontrast CT scan of patient in July 1978, showing a high density lesion consistent with blood within the previously demonstrated mass.

\section{Discussion}

This is an unusual case because haemorrhage associated with an intracranial neoplasm is a rare event. ${ }^{2}$ Mutlu, et $a l^{3}$ reported a $0.9 \%$ (2 of 225 cases) incidence of intracerebral haemorrhage secondary to brain tumour, and Yasargil ${ }^{4}$ reported a $1-2 \%$ incidence of brain tumour in patients presenting with subarachnoid haemorrhage. Intracranial haemorrhage in association with meningioma is very infrequent as is demonstrated by examination of two large series of meningiomas collected by

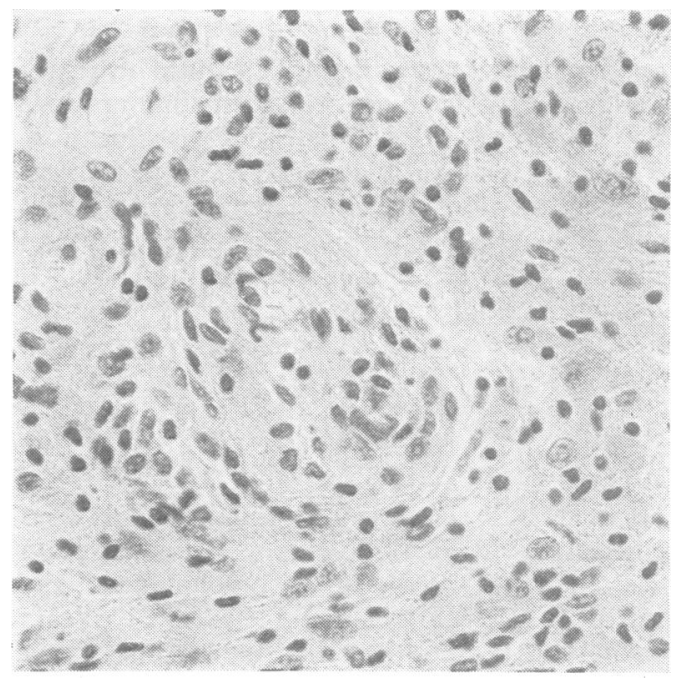

Fig 3 Photomicrograph of transitional meningioma renoved from our patient. $H \& E \times 320$.

Cushing and Eisenhardt ${ }^{5}$ (313 cases), and Hoessly and Olivecrona ${ }^{6}$ ( 280 cases of parasagittal meninioma). Neither series reported any case of massive haemorrhage. By contrast, in our case a transitional cell parasagittal meningioma underwent spontaneous, symptomatic, intratumoral haemorrhage.

Mechanisms responsible for haemorrhage within tumours are not completely understood. Glioblastoma multiforme and oligodendroglioma are the primary brain tumours which bleed most 
frequently. ${ }^{7}$ Haphazard endothelial proliferation and tumour necrosis within glioblastomas may be factors which cause this haemorrhagic tendency. ${ }^{8}$ Hypernephroma and malignant melanoma are the metastatic brain tumours which bleed most frequently, and the incompletely formed, friable blood vessels associated with the rapid growth of metastatic tumours may be responsible for their bleeding tendency. ${ }^{7}$ Factors responsible for haemorrhage within benign intracranial tumours, such as meningiomas, are less obvious. Angioblastic meningiomas characteristically are composed of abnormal blood vessels $^{9}$ and meningiomas of other cell types can contain foci of abnormal vessels; this abnormal vascularity could be related to tumour-associated haemorrhage. ${ }^{10}$ It is possible that blood vessels supplying a meningioma undergo compensatory enlargement with weakening of their wall and create the potential for tumour associated haemorrhage. ${ }^{11}$ It has also been postulated that cerebral oedema and venous obstruction, which are commonly associated with meningiomas, can cause infarction and subsequent haemorrhage. ${ }^{10,12}$

Only 43 other cases of haemorrhage associated with meningioma were found in a review of the literature; these cases as well as our case are tabulated in table 1. The type of tumour most frequently associated with haemorrhage was the

Table 1 Data on 44 patients with meningioma associated haemorrhage

\begin{tabular}{|c|c|c|c|c|c|c|c|c|}
\hline Reference & $\begin{array}{l}\text { Age } \\
(y r)\end{array}$ & Sex & $\begin{array}{l}\text { Haemorrhage } \\
\text { type* }\end{array}$ & $\begin{array}{l}\text { Tumour } \\
\text { site }\end{array}$ & $\begin{array}{l}\text { Tumour } \\
\text { histology } \ddagger\end{array}$ & $\begin{array}{l}\text { Patient's } \\
\text { outcome } \$\end{array}$ & Operation $\|$ & $\begin{array}{l}\text { Symptom } \\
\text { onset } 9\end{array}$ \\
\hline Present Case & 77 & $\mathbf{M}$ & IT & $\mathbf{R}$ parasag & Transitional & Morb & Resection & Slow \\
\hline \multicolumn{9}{|l|}{ Askenasy and Behmoaram, } \\
\hline $1960^{11} 1$ & 34 & $\mathrm{~F}$ & SA & $L$ lat vent & Syncytial & Died & Resection & Sudden \\
\hline 2 & 38 & $\mathrm{~F}$ & $\mathbf{S A}$ & $\mathrm{L}$ lat vent & Fibrous & Died & Resection & Sudden \\
\hline 3 & 32 & $\mathbf{M}$ & IV & $\mathbf{R}$ lat vent & Transitional & Morb & Resection & Slow \\
\hline Bilodeau and Beraud, $1966^{13}$ & 46 & $\mathbf{M}$ & IC, IT & $\mathbf{R}$ convex & Syncytial & Died & Evacuation & Slow \\
\hline Bingas and Meese, $1966^{14}$ & 65 & $\mathrm{~F}$ & SD & $\mathbf{R}$ convex & Syncytial & NI & Resection & Sudden \\
\hline Budny et al, 197715 & 60 & $\mathbf{M}$ & IC, IT & $\mathbf{R}$ convex & Malignant & Died & Resection & Slow \\
\hline Cusick and Bailey, $1972^{16}$ & 47 & $\mathbf{F}$ & SD & $\mathbf{R}$ convex & Nonspecified & Died & None & Slow \\
\hline El-Banhawy and Walter, 196212 & 20 & $\mathbf{M}$ & SA & $\mathrm{L}$ parasag & Syncytial & Morb & Resection & Slow \\
\hline Everett et al, 197917 & 65 & $\mathbf{M}$ & IC, IT, IV & $\mathbf{R}$ convex & Syncytial & Died & Resection & Sudden \\
\hline Flynn and Karpas, $1971^{18}$ & 78 & $\mathrm{~F}$ & IT, SA & L convex & Nonspecified & Died & None & Slow \\
\hline Goran et al, 1965,19 1 & 65 & $\mathbf{M}$ & IC, IT & $\mathbf{R}$ convex & Syncytial & Died & Evacuation & Sudden \\
\hline & 68 & $\mathrm{~F}$ & IT, SA & R sphenoid & Syncytial & Died & Resection & Sudden \\
\hline & 46 & $\mathbf{M}$ & IT & $\mathbf{R}$ parasag & Syncytial & Died & None & Slow \\
\hline 4 & 55 & $\mathbf{M}$ & IC, SA & $R$ lat vent & Malignant & Morb & Resection & Sudden \\
\hline 5 & 42 & $\mathrm{~F}$ & IT & L convex & Syncytial & Died & None & Sudden \\
\hline Gruszki^wicz et al, 196910 & 18 & $\mathbf{M}$ & IC, SA & $\mathbf{R}$ convex & Fibrous & Morb & Resection & Sudden \\
\hline Hung et al, $1972^{20}$ & 42 & $\mathbf{F}$ & IT & L convex & Fibrous & Morb & Resection & Slow \\
\hline \multirow[t]{4}{*}{ Modesti et al, 197621 1} & 59 & $\mathbf{M}$ & IC, SA, SD & L sphenoid & Syncytial & $\mathrm{NI}$ & Resection & Sudden \\
\hline & 49 & $\mathbf{F}$ & IC, SA, SD & L parasag & Syncytial & Morb & Resection & Slow \\
\hline & 72 & $\mathbf{F}$ & $\mathrm{SA}, \mathrm{SD}$ & L parasag & Angioblastic & Died & Resection & Slow \\
\hline & 69 & $\mathbf{M}$ & SD & L convex & Syncytial & $\mathrm{NI}$ & Resection & Slow \\
\hline \multirow[t]{2}{*}{ Mor)re, 195422} & 72 & $\mathbf{M}$ & SA & Bilat parasag & Fibrous & Died & None & Sudden \\
\hline & 66 & $\mathbf{F}$ & IV, SA & $\mathbf{R}$ convex & Angioblastic & Died & None & Slow \\
\hline Nakao et al, $1977^{9}$ & 21 & $\mathbf{M}$ & IC, SA & $\mathbf{R}$ convex & Angioblastic & Morb & Resection & Slow \\
\hline Nasiar and Correll, $1968^{23}$ & 34 & $\mathbf{M}$ & IV, SA & Spinal & Angioblastic & Died & None & Slow \\
\hline Ohaegbulam, 197724 & 40 & $\mathbf{M}$ & $\mathrm{SA}$ & L sphenoid & Fibrous & Died & None & Sudden \\
\hline \multirow[t]{2}{*}{ Ros snberg et al, $1975^{25} 1$} & 44 & $\mathbf{M}$ & SA & R Meckel's Cv & Angioblastic & Morb & Resection & Slow \\
\hline & 48 & $\mathrm{~F}$ & SA & L Meckel's CV & Nonspecified & Morb & Resection & Slow \\
\hline Smith et al, 197526 & 14 & $\mathrm{~F}$ & SA & L lat vent & Fibrous & NI & Resection & Sudden \\
\hline Walsh et al, 197727 & 77 & $\mathrm{~F}$ & $\mathrm{IT}, \mathrm{SD}$ & Bilat convex & Syncytial & Died & Resection & Slow \\
\hline \multirow{2}{*}{ Yasargil and So, $1976^{28} 1$} & 50 & $\mathrm{~F}$ & IT, SA, SD & L post fossa & Transitional & Morb & Resection & Sudden \\
\hline & 47 & $\mathrm{~F}$ & IT, SA & L post fossa & Nonspecified & Morb & Resection & Slow \\
\hline Skultety, $1968^{29}$ & 58 & M & IC, IT, SA, SD & R sphenoid & Fibrous & - & Resection & Slow \\
\hline Fukumitsu et al, 197330 & 49 & $\mathbf{F}$ & IC & Parasag & Syncytial & - & - & - \\
\hline Therkelsen, $1961^{31}$ & - & - & SD & Convex & Nonspecified & - & Nonspecified & - \\
\hline Locksley et al, $1966^{32}$ & - & - & SA & Parasag & Nonspecified & - & - & - \\
\hline Globus and Sapirstein, $1942^{8}$ & - & - & SA & - & Nonspecified & - & - & - \\
\hline McLaurin and Helmer, $1962^{33}$ & - & - & SA & - & Angioblastic & - & - & - \\
\hline \multicolumn{9}{|l|}{ Russell and Rubinstein, } \\
\hline 1977341 & - & - & IC, SD & - & Nonspecified & - & - & - \\
\hline 2 & - & - & IC & - & Nonspecified & - & - & - \\
\hline \multirow[t]{2}{*}{ Zimmerman, 1963351} & - & - & IC & - & Angioblastic & 一 & - & - \\
\hline & - & - & IC & - & Angioblastic & - & - & - \\
\hline Drake and McGee 196136 & - & - & - & 一 & Nonspecified & - & - & - \\
\hline
\end{tabular}

* IC-intracerebral; IT-intratumoral; IV-intraventricular; SD-subdural; SA-subarazhnoid.

+ Convexity refers to tumours located on either the frontal, parietal, temporal or ozcipital lobz.

$\ddagger$ Classification according to Russell and Rubinstein (1977).

$\$$ Morbidity-any permanent neurologic deficit; Normal-complete resovery.

Resection refers to total or subtotal resection of tumour and evacuation of hematoma; Evacuation refers to only evacuation of həmato na.

Slow refers to symptoms relating to the tumour and/or hematoma being present more than 24 hours prior to hospitalization; Suddən refers to symptoms being present less than 24 hours prior to hospitalization. 
syncytial meningioma (32\%), followed by angioblastic ( $18 \%)$. The greatest number of meningiomas were located on the convexities, but were also found infratentorially, intraventricularly, and in the spinal canal. Tumours occurred with equal frequency on the right and left sides. Clinical data revealed that the average age at the time of haemorrhage was 50 years, and there was an equal sex incidence. Symptoms from the haemorrhage were slow in onset in just over $50 \%$ of patients; in the others the event was rapid in onset and usually catastrophic. Many patient had more than one type of haemorrhage associated with their meningioma; however, the most frequently occurring haemorrhage was subarachnoid $(35 \%)$. Of the 35 patients where operative data is available, 24 had craniotomy for resection of tumour. Of the 33 patients where outcome is known, only $4(1 \%)$ recovered completely and all these patients had had tumour resection. $52 \%$ of these patients died. Interestingly, those patients who had no surgery or only haematoma evactuation (10 cases) all died, whereas the outcome was more favourable when tumour resection was accomplished at the time of the craniotomy (table 2).

By relating data from this series of meningiomas associated with haemorrhage to data obtained from a large series of meningiomas which reports the incidence of histological types, it is possible to calculate an approximate "relative bleeding tendency" for a given histological type of tumour. Angioblastic meningiomas comprise $8 \%$ of the 1197 surgically verified intracranial and intraspinal

Table 2 Correlation of patient outcome versus type of operation performed

\begin{tabular}{lcll}
\hline \multirow{2}{*}{ Patient outcome } & \multicolumn{2}{l}{ Operation performed } \\
\cline { 2 - 4 } & Resection & Evacuation & None \\
\hline Died & 7 & 2 & 8 \\
Morbidity & 12 & 0 & 0 \\
Normal & 4 & 0 & 0 \\
\hline
\end{tabular}

Table 3 Relative bleeding tendency of meningiomas to tumour histology calculated by relating the present series with Jellinger and Slowik $(1975)^{37}$

\begin{tabular}{lccc}
\hline Histology & $\begin{array}{c}\text { Distribution of } \\
\text { bleeding meningiomas* }\end{array}$ & $\begin{array}{l}\text { Distribution of } \\
\text { meningiomas } \dagger\end{array}$ & $\begin{array}{c}\text { Approx relative } \\
\text { bleeding index }\end{array}$ \\
\hline Angioblastic & $8(18)$ & $97(8)$ & 2 \\
Transitional & $3(7)$ & $255(21)$ & $0 \cdot 3$ \\
Syncytial & $14(32)$ & $749(63)$ & $0 \cdot 5$ \\
Fibrous & $7(16)$ & $82(7)$ & 2 \\
Malignant & $2(4)$ & $14(1)$ & 4 \\
Nonspecified & $10(23)$ & - & - \\
\multicolumn{1}{c}{ TOTAL } & 44 & 1,197 & - \\
\hline
\end{tabular}

* Present series.

† Jellinger \& Slowik (1975). ${ }^{37}$

Percentages in parentheses
Table 4 Relative bleeding tendency of meningiomas according to tumour location

\begin{tabular}{llll}
\hline Location & $\begin{array}{l}\text { Distribution of } \\
\text { bleeding } \\
\text { meningiomas* }\end{array}$ & $\begin{array}{l}\text { Distribution of } \\
\text { meningiomas } \dagger\end{array}$ & $\begin{array}{c}\text { Approx relative } \\
\text { bleeding index }\end{array}$ \\
\hline Parasagittal & $8(22)$ & $194(16 \cdot 5)$ & $1 \cdot 3$ \\
Convexity & $15(40)$ & $460(38 \cdot 5)$ & 1 \\
Sphenoid & $4(11)$ & $107(9)$ & $1 \cdot 2$ \\
Posterior Fossa & $2(5)$ & $90(7 \cdot 5)$ & $0 \cdot 7$ \\
Ventricular & $5(14)$ & $6(0 \cdot 5)$ & 27 \\
Meckel's Cave & $2(5)$ & none & - \\
Spinal & $1(3)$ & $208(17)$ & $0 \cdot 16$ \\
Others & none & $132(11)$ & - \\
\multicolumn{1}{c}{ TOTAL } & 37 & 1197 & - \\
\hline
\end{tabular}

* Present series.

† Jellinger and Slowik (1975) 37

Percentages in parentheses

meningiomas reported by Jellinger and Slowik $;^{37}$ however, $18 \%$ of the meningiomas associated with haemorrhage reported in the present study were angioblastic. This suggests that angioblastic meningiomas have a tendency to bleed more than two times more frequently than all other meningiomas combined. By using the same method of calculation, the relative bleeding tendency for transitional meningioma is $\mathbf{0} \cdot \mathbf{3}$, for syncytial, $\mathbf{0} \cdot \mathbf{5}$, for fibrous, 2 , and for malignant meningioma, 4 (table 3). If tumour location is considered, the greatest relative bleeding tendency is $\mathbf{2 7}$ for intraventricular meningioma and the least, $0 \cdot 16$ for spinal meningioma (table 4). Parasagittal, convexity, sphenoid, and posterior fossa meningiomas all have a relative bleeding tendency of approximately 1 . While the small number of cases of haemorrhage in association with meningioma does not allow one to place great significance on these calculations, if they are applied to our patient, his meningioma had a relatively low bleeding potential because of location (parasagittal) and histology (transitional). His recovery with minimal morbidity relates both to the type of haemorrhage (intratumoural only) and to the fact that he had definitive surgery. However, his benign clinical course must be considered somewhat unusual because among the conclusions which can be drawn from this literature review are that haemorrhage associated with a meningioma is a very serious event and is associated with a high mortality. To our knowledge, the present case is the first reported where haemorrhage into a meningioma has been documented by serial CT scans. CT scans may allow earlier diagnosis of a haemorrhagic event in association with a benign intracranial tumour and thus improve the ultimate prognosis in patients with these tumours. From our study it is apparent that definitive surgery with combined evacuation of the haematoma and tumour resection provides the best chance for recovery with the least morbidity. 
The authors thank Leslie Zatz, MD for reviewing the manuscript and making constructive criticism, Palo Alto Veterans Administration Medical Center's Medical Media Department for the photographs, and to Ruth Uhrhammer for preparation of the manuscript.

\section{References}

1 Skullerud K, Löken AC. The prognosis in meningiomas. Acta Neuropathol (Berl) 1974; 29:337-44.

2 Scott M. Spontaneous intracerebral hematoma caused by cerebral neoplasms. J Neurosurg 1975; 42:338-42.

3 Mutlu N, Berry RG, Alpers BJ. Massive cerebral hemorrhage. Arch Neurol 1963; 8:644-61.

4 Yasargil MG. Die subarachnoidale Blutung. Schweiz Med Wochenschr 1969; 99:1629-32.

5 Cushing H, Eisenhardt L. Meningiomas. Springfield, Charles C Thomas, 1938.

6 Hoessly GF, Olivecrona H. Report on 280 cases of verified parasagittal meningioma. J Neurosurg 1955 ; 12:614-26.

7 Zülch KJ. Neuropathology of intracranial haemorrhage. Prog Brain Res 1968; 30:151-65.

8 Globus JH, Sapirstein M. Massive hemorrhage into brain tumour. JAMA 1942; 120:348-52.

9 Nakao S, Sato S, Ban S, Inutsuka N, Yamamoto T, Ogata M. Massive intracerebral hemorrhage caused by angioblastic meningioma. Surg Neurol 1977; 7:245-8.

10 Gruszkiewicz J, Doron Y, Gellei B, Peyer E. Massive intracerebral bleeding due to supratentorial meningioma. Neurochirurgia (Stuttg) 1969; 12:107-11.

11 Askenasy HM, Behmoaram AD. Subarachnoid hemorrhage in meningiomas of the lateral ventricle. Neurology (Minneap.) 1960; 10:484-9.

12 El-Banhawy A, Walter W. Meningiomas with acute onset. Acta Neurochir (Wien) 1962; 10:194-206.

13 Bilodeau B, Beraud R. Hémorrhgie dans un méningiome. Can Med Assoc J 1960; 95:682-4.

14 Bingas B, Meese M. Subdurales Hämatom seltener Ätiologie (Fallmitteilung). Nevenarzt 1966; 37:175-7.

15 Budny JL, Glasauer FE, Sil R. Rapid recurrence of meningioma causing intracerebral hemorrhage. Surg Neurol 1977; 8:323-5.

16 Cusick JF, Bailey OT. Association of ossified subdural hematomas and a meningioma. J Neurosurg $1972 ; 37: 731-4$.

17 Everett BA, Kusske JA, Pribram HW. Anticoagulants and intracerebral hemorrhage from an unsuspected meningioma. Surg Neurol 1979; 11:233-5.
18 Flynn JT, Karpas CM. Intracranial lesion with haemorrhage. NY State J Med 1971; 71:1951-9.

19 Goran A, Ciminello VJ, Fisher RG. Haemorrhage into meningiomas. Arch Neurol 1965; 13:65-9.

20 Hung C, Chang W, Yao Y. Post-traumatic intracranial meningioma. J Formosan Med Assoc 1972; 71:214-9.

21 Modesti LM, Binet EF, Collins GH. Meningiomas causing spontaneous intracranial hematomas. $J$ Neurosurg 1976; 45:437-41.

22 Moore MT. The fate of clinically unrecognized intracranial meningiomas. Neurology (Minneapolis) 1954; 4:837-56.

23 Nassar SI, Correll JW. Subarachnoid haemorrhage due to spinal cord tumours. Neurology (Minneapolis). 1968; 18:87-94.

24 Ohaegbulam SC. Sudden death from an asymptomatic sphenoid ridge meningioma. J Neurol 1977; 215:291-4.

25 Rosenberg GA, Herz DA, Leeds N, Strully K. Meckel's cave meningiomas with subarachnoid haemorrhage. Surg Neurol 1975; 3:333-6.

26 Smith VR, Stein PS, MacCarty CS. Subarachnoid haemorrhage due to lateral ventricular meningiomas. Surg Neurol 1975; 4:241-3.

27 Walsh JW, Winston KR, Smith T. Meningioma with subdural hematoma. Surg Neurol 1977; 8:293-5.

28 Yasargil MG, So SC. Cerebellopontine angle meningioma presenting as subarachnoid haemorrhage. Surg Neurol 1976; 6:3-6.

29 Skultety FM. Meningioma simulating ruptured aneurysm. $J$ Neurosurg 1968; 28:380-2.

30 Fukumitsu T, Yoshida Y, Yamashita J. Massive intracerebral haemorrhage due to parasagittal meningioma. Brain Nerve (Tokyo) 1973; 25:911-4.

31 Therkelsen J. The diagnostic value of cerebral angiography in patients with apoplectic symptoms. Acta Psychiatr Scand (suppl 150), 1961; 36:129-32.

32 Locksley HB, Sahs AL, Sandler R. Report on the cooperative study of intracranial aneurysms and subarachnoid haemorrhage. Section III. J Neurosurg 1966; 24:1034-56.

33 McLaurin RL, Helmer FA. Errors in diagnosis of intracranial tumours. JAMA 1962; 180:1011-6.

34 Russell DS, Rubinstein LS. Pathology of tumours of the nervous system, 4th Ed., Baltimore: Williams and Wilkins, 1977.

35 Zimmerman HM. Personal communication in Goran, et al. ${ }^{19}$

36 Drake CG, McGee D. Apoplexy associated with brain tumours. Can Med Assoc J 1961; 84:303-5.

37 Jellinger K, Slowik F. Histological subtypes and prognostic problems in meningiomas. $J$ Neurol 1975; 208:279-98. 